\title{
METODE PEMECAHAN MASALAH INTEGER PROGRAMMING
}

Oleh : Siti Maslihah

Fakultas Ilmu Tarbiyah dan Keguruan Universitas Islam Negeri Walisongo Email : ratik20@yahoo.com

\begin{abstract}
Abstrak
Variabel keputusan dalam penyelesaian masalah program linier sering kali berupa bilangan pecahan. Dalam beberapa kasus tertentu ada yang menghendaki solusinya berupa bilangan bulat (integer). Solusi integer yang didapatkan dengan cara pembulatan tidak menjamin berada di daerah fisibel. Untuk memperoleh solusi integer antara lain dengan metode Cutting Plane Algorithm atau Branch and Bound. Kelebihan metode Cutting Plane Algorithm adalah cukup efektif mempersingkat hitungan, sedangkan kelebihan metode Branch and Bound adalah memiliki tingkat kesalahan yang sedikit akan tetapi memerlukan perhitungan yang cukup lama.
\end{abstract}

\section{Abstract}

Decision variables in the problem solving linear programs are often in the form of fractions. In some cases there are specific desires the solution in the form of an integer (integer). Integer solution is obtained by way of rounding does not warrant being in the area of fisibel. To obtain integer solutions, among others, by the method of Cutting Plane Algorithm or Branch and Bound. The advantages of the method of Cutting Plane Algorithm is quite effectively shorten the matter, while the advantages of the method of Branch and Bound the error level is to have a little but requires quite a long calculation.

Key Word : integer linier programming; Cutting Plane Algorithm; Branch and Bound

\section{A. Pendahuluan}

Model dalam masalah program linier salah satunya membolehkan variabel keputusannya berupa bilangan pecahan, jadi solusinya merupakan solusi yang kontinu dengan menggunakan asumsi divisibilitas. Dalam beberapa kasus, asumsi divisibilitas tidak dapat diterapkan dan tidak dapat diterima. Misalnya suatu solusi menghasilkan 4.23 buah pesawat terbang yang akan diproduksi agar keuntungan maksimum. Hal ini tidak dapat diterima karena pesawat yang dibuat seharusnya 4 atau 5 buah. Masalah solusi yang tidak bulat ini dapat diatasi dengan menggunakan optimisasi 
dengan solusi bulat yang disebut dengan integer programming. Model dari integer programming sebagai berkut:

Maksimumkan $\sum_{j=1}^{n} c_{j} x_{j}$

Dengan kendala $\sum_{j=1}^{n} a_{i j} x_{j}=b_{i}, \quad i=1,2,3, \ldots, m$

$$
x_{j} \geq 0
$$

$x_{j}$ integer, untuk beberapa atau untuk semua $j=1,2,3, \ldots, n$

\section{B. Contoh-contoh masalah Integer Programming}

Terdapat mixed integer programming dan pure integer programming dan $0-1$ integer programming. Dikatakan mixed integer programming jika tidak semua variabel keputusannya integer, sedangkan dikatakan pure integer programming jika semua variabel keputusannya bertipe integer, dan dikatakan $0-1$ integer programming jika solusi yang diharapkan adalah hanya bertipe 0 atau 1.

Beberapa contoh masalah dari masing-masing tipe $0-1$ integer programming adalah sebagai berikut:

\section{Contoh pure integer programming}

Pemilik took merencanakan membeli mesin pencetak dan mesin bubut. Pemilik memprediksi setiap mesin pencetak akan menaikkan keuntungan sebesar $\$ 100 /$ hari dan mesin bubut akan menaikkan keuntungan $\$ 150 /$ hari. Luas tempat dan harga masing-masing sebagai berikut:

\begin{tabular}{|l|l|l|}
\hline Mesin & Luas tempat $(\mathrm{ft})$ & Harga beli $(\$)$ \\
\hline Pencetak & 15 & 8000 \\
\hline Bubut & 30 & 4000 \\
\hline
\end{tabular}

Anggaran pembelian mesin adalah $\$ 40.000$, sedangkan tempat tersedia 200 feet persegi. Pemilik ingin mengetahui berapa banyak mesin yang dapat dibeli supaya keuntungan maksimum. Dalam hal ini tidak diperbolehkan menghasilkan solusi yang pecahan.

Formulasi masalah untuk kasus tersebut adalah:

Maksimumkan $Z=100 x_{1}+150 x_{2}$ 
Dengan kendala $15 x_{1}+30 x_{2} \leq 200$

$$
\begin{aligned}
& 8000 x_{1}+4000 x_{2} \leq 40000 \\
& x_{1}, x_{2} \geq 0 \text { dan integer }
\end{aligned}
$$

\section{Contoh 0-1 integer programming}

Bapeda sebuah kota merencanakan untuk membangun fasilitas rekreasi yaitu kolam renang, lapangan tenis, lapangan atletik dan gelanggang olah raga. Pengguna, biaya dan lahan yang diperlukan disajikan pada tabel berikut:

\begin{tabular}{|l|c|c|c|}
\hline Fasilitas Rekreasi & $\begin{array}{c}\text { Banyaknya pengguna } \\
\text { (orang/hari) }\end{array}$ & Biaya (\$) & $\begin{array}{c}\text { Luas lahan } \\
\text { (are) }\end{array}$ \\
\hline Kolam renang & 300 & 35.000 & 4 \\
\hline Lapangan tenis & 90 & 10.000 & 2 \\
\hline Lapangan atletik & 400 & 25.000 & 7 \\
\hline $\begin{array}{l}\text { Gelanggang Olah } \\
\text { raga }\end{array}$ & 150 & 90.000 & 3 \\
\hline
\end{tabular}

Anggaran yang disediakan $\$ 120.000$ dan luas lahan 12 are. Karena ada pada lahan yang sama, lahan kolam renang atau lapangan tenis hanya akan didirikan salah satu saja. Bapeda ingin mengetahui fasilitas mana saja yang harus didirikan agar pengguna menjadi maksimum.

Formulasi masalah untuk kasus tersebut adalah:

Misalkan $x_{1}$ : Kolam renang

$x_{2}$ : Lapangan tenis

$x_{3}$ : Lapangan atletik

$x_{4}$ : Gelanggang olah raga

Maksimumkan $Z=300 x_{1}+90 x_{2}+400 x_{3}+150 x_{4}$

Dengan kendala $35.000 x_{1}+10.000 x_{2}+25.000 x_{3}+90.000 x_{4} \leq 120.000$

$4 x_{1}+2 x_{2}+7 x_{3}+3 x_{4} \leq 12$

$x_{1}+x_{2} \leq 1$

$x_{1}, x_{2}, x_{3}, x_{4}=0$ atau 1 


\section{Contoh mixed linier programming}

Seorang pengusaha memiliki kelebihan uang \$250.000 dan akan diinvestasikan pada 3 alternatif, yaitu: kondominium, tanah dan obligasi. Dia ingin menginvestasikan uangnya dengan tujuan pengembalian terbesar diperoleh pada akhir tahun.

Data jenis investasi:

\begin{tabular}{|l|l|l|l|}
\hline Jenis investasi & Harga & Ketersediaan & $\begin{array}{l}\text { Keuntungan per } \\
\text { tahun }\end{array}$ \\
\hline Kondominium & $\$ 50.000 /$ unit & 4 unit & $\$ 9.000$ \\
\hline Tanah & $\$ 12.000 /$ are & 15 are & $\$ 1500$ \\
\hline Obligasi & $\$ 8.000 /$ obligasi & 20 obligasi & $\$ 1000$ \\
\hline
\end{tabular}

Formulasi masalah tersebut adalah:

Maksimumkan $Z=9000 x_{1}+1500 x_{2}+1000 x_{3}$

Dengan kendala $50.000 x_{1}+12.000 x_{2}+8000 x_{3} \leq 250.000$

$$
\begin{aligned}
& x_{1} \leq 4 \\
& x_{2} \leq 15 \\
& x_{3} \leq 20 \\
& x_{2} \geq 0 \\
& x_{1}, x_{3} \geq 0 \text { dan integer }
\end{aligned}
$$

Untuk mendapatkan solusi yang integer dari masalah program linier seperti contoh tersebut di atas cukup digunakan metode simpleks yang biasa kemudian membulatkan solusi pecah optimum yang didapatkan. Bukan suatu pekerjaan yang mudah untuk membulatkan solusi pecah agar menjadi bulat dan tetap memenuhi semua kendala dan tidak menyimpang jauh dari solusi bulat yang tepat.

\section{Solusi bulat/integer}

Ada beberapa cara yang dapat digunakan untuk mendapatkan solusi bulat optimum antara lain pembulatan, pendekatan grafik, pendekatan Gomory (Cutting Plane Algorithm) dan metode Branch and Bound. 
1. Metode pembulatan

Metode pembulatan merupakan suatu cara yang termudah, praktis dan efisien dalam menyelesaikan masalah integer programming. Cara yang digunakan yaitu dengan membulatkan nilai variabel keputusan yang didapatkan melalui metode simpleks biasa. Metode ini praktis dalam hal waktu, biaya dan tenaga untuk memperoleh suatu solusi. Contoh banyaknya pakaian yang harus diproduksi adalah sebanyak 5734,34 maka dengan menggunakan metode pendekatan menjadi 5734 potong pakaian. Dalam beberapa kasus metode pembulatan kurang tepat untuk digunakan karena ada kemungkinan solusi pembulatan yang diperoleh lebih jelek dari pada solusi bulat sesungguhnya, atau ada kemungkinan juga solusi pembulatan yang didapatkan tidak layak. Hal ini membawa konsekuensi besar jika produk-produk yang dibulatkan seperti pesawat terbang komersial, kapal perang atau yang lainnya yang mempunyai nilai jual yang tinggi apabila dibulatkan ke bilangan bulat terdekat.

Masalah-masalah yang dapat muncul dari metode pembulatan akan tampak dalam beberapa masalah program linier berikut:

a. Maksimalkan $Z=3 x_{1}+2 x_{2}$

Dengan kendala $5 x_{1}+x_{2} \geq 10$

$$
\begin{aligned}
& 2 x_{1}+x_{2} \leq 8 \\
& x_{2} \geq 2 \\
& x_{1} \geq 0
\end{aligned}
$$

Pada masalah tersebut jika diselesaikan menggunakan metode simpleks maka akan didapatkan solusi $x_{1}=0.667, x_{2}=6.667$ dan $Z=15.333$. Jika menggunakan pembulatan nilai terdekat untuk mendapatkan solusi integer maka akan didapatkan $x_{1}=1, x_{2}=7$ dan $Z=17$, solusi tersebut bukan solusi yang layak karena tidak memenuhi salah satu kendala. Solusi integer yang sebenarnya adalah $x_{1}=1, x_{2}=6$ dan $Z=15$.

b. Maksimumkan $Z=4 x_{1}+7 x_{2}$

Dengan kendala $x_{1}+x_{2} \leq 7$ 


$$
\begin{aligned}
& 5 x_{1}+9 x_{2} \leq 45 \\
& x_{1} \leq 3 \\
& x_{2} \geq 3
\end{aligned}
$$

Pada masalah tersebut jika diselesaikan menggunakan metode simpleks maka akan didapatkan solusi $x_{1}=3, x_{2}=3.333$ dan $Z=35.333$. Jika menggunakan pembulatan nilai terdekat untuk mendapatkan solusi integer maka akan didapatkan $x_{1}=3, x_{2}=3$ dan $Z=33$. Solusi integer yang sebenarnya adalah $x_{1}=0, x_{2}=5$ dan $Z=35$. Tampak nilai optimal sebenarnya lebih besar dibandingkan dengan pendekatan pembulatan.

Berdasarkan contoh-contoh di atas dengan metode pembulatan untuk mendapatkan solusi integer memungkinkan mendapatkan solusi yang tidak layak, atau nilai optimal solusi sebenarnya lebih besar daripada solusi optimal.

\section{Metode Cutting Planes}

Metode Cutting Planes merupakan salah satu metode yang digunakan untuk menyelesaikan masalah program linier untuk variabelnya harus bulat, baik bulat murni maupun campuran dengan penambahan batasan baru yang disebut dengan gomory. Kendala gomory diberikan jika variabel keputusan belum bulat (bernilai pecahan). Batasan-batasan tersebut secara efektif akan menyingkirkan beberapa ruang penyelesaian yang tidak berisi titik bilangan bulat yang layak, tetapi tidak pernah menyingkirkan satupun titik bilangan bulat yang layak.

Langkah-langkah penyelesaian metode Cutting Planes:

a. Selesaikan masalah integer programming dengan menggunakan metode simpleks.

b. Periksa solusi optimum yang diperoleh dari langkah 1, jika variabel keputusan solusi optimum sudah bernilai bulat (integer) maka proses selesai. Jika variabel keputusan pada solusi optimum masih bernilai pecahan maka proses berlanjut ke tahap berikutnya.

c. Buat batasan/kendala Gomory dan selesaikan dengan metode dual simpleks.

d. Kembali ke langkah b. 
Tabel solusi optimal Program linier

\begin{tabular}{|l|l|l|l|l|l|l|l|}
\hline $\mathrm{B}$ & $\mathrm{X} 1$ & $\cdots$ & $\mathrm{Xm}$ & $\mathrm{S} 1$ & $\cdots$ & $\mathrm{Sn}$ & $\begin{array}{l}\text { Nilai Kanan/ } \\
\text { Solusi }\end{array}$ \\
\hline $\mathrm{X} 1$ & 1 & $\cdots$ & 0 & $a_{11}$ & $\cdots$ & $\mathrm{Cn}$ & $b_{1}$ \\
\hline$\cdots$ & 0 & $\cdots$ & $\cdots$ & $\cdots$ & $\cdots$ & $\cdots$ & $\cdots$ \\
\hline $\mathrm{Xm}$ & 0 & $\cdots$ & 1 & $a_{m 1}$ & $\cdots$ & $a_{m n}$ & $b_{m}$ \\
\hline $\mathrm{Z}$ & 0 & $\cdots$ & 0 & $c_{1}$ & $\cdots$ & $c_{n}$ & $b_{0}$ \\
\hline
\end{tabular}

Dengan $x_{i}$ adalah variabel basis, $i=1,2,3, \ldots, m$

$s_{j}$ adalah variabel non basis, $j=1,2,3, \ldots, n$

Perhatikan persamaan ke $-i$ di mana variabel $x_{i}$ diasumsikan bernilai non integer.

$x_{i}=b_{i}-\sum a_{i j} s_{j}$, dengan $b$ non integer (baris sumber).

Kemudian pisahkan $b_{i}$ dan $a_{i j}$ menjadi bagian yang bulat dan pecahan non negatif seperti berikut: $b_{i}=b_{i}^{\prime}+f_{i}$ dan, $a_{i j}=a_{i j}^{\prime}+f_{i}$ dengan $0 \leq f_{i} \leq 1$. Misalnya:

\begin{tabular}{|c|c|c|}
\hline$b_{i}$ & $b_{i}^{\prime}$ & $f_{i}$ \\
\hline$\frac{3}{2}$ & 1 & $\frac{1}{2}$ \\
\hline$\frac{7}{8}$ & 0 & $\frac{7}{8}$ \\
\hline$\frac{7}{3}$ & 2 & $\frac{1}{3}$ \\
\hline$\frac{7}{3}$ & -3 & $\frac{2}{3}$ \\
\hline-1 & -1 & 0 \\
\hline$-\frac{2}{5}$ & -1 & $\frac{3}{5}$ \\
\hline
\end{tabular}

Tambahan kendala Gomory dalam bentuk: $s_{g}-\sum f_{i j} s_{j}=-f_{i}$ dengan $s_{g}$ adalah variabel slack Gomory ke g. Pada umumnya, 
persamaan kendala yang berhubungan dengan solusi pecah dipilih untuk menghasilkan suatu kendala Gomory. Namun, sebagai aturan main biasanya dipilih persamaan yang memiliki $f_{i}$ maksimum.

Tabel baru setelah penambahan kendala Gomory

\begin{tabular}{|l|l|l|l|l|l|l|l|l|}
\hline $\mathrm{B}$ & $x_{1}$ & $\cdots$ & $x_{m}$ & $s_{1}$ & $\cdots$ & $s_{n}$ & $s_{g}$ & $\begin{array}{l}\text { Nilai Kanan/ } \\
\text { Solusi }\end{array}$ \\
\hline$x_{1}$ & 1 & $\cdots$ & 0 & $a_{11}$ & $\cdots$ & $a_{i n}$ & 0 & $b_{1}$ \\
\hline$\cdots$ & 0 & $\cdots$ & $\cdots$ & $\cdots$ & $\cdots$ & $\cdots$ & $\cdots$ & $\cdots$ \\
\hline$x_{m}$ & 0 & $\cdots$ & 1 & $a_{m 1}$ & $\cdots$ & $a_{m n}$ & 0 & $b_{m}$ \\
\hline$s_{g}$ & 0 & $\cdots$ & 0 & $-f_{i 1}$ & $\cdots$ & $-f_{i n}$ & 1 & $-f_{i}$ \\
\hline $\mathrm{Z}$ & 0 & $\cdots$ & 0 & $c_{1}$ & $\cdots$ & $c_{n}$ & 0 & $b_{0}$ \\
\hline
\end{tabular}

Penyelesaian optimal masalah primal tersebut menggunakan metode dual simpleks karena didapatkan solusi optimal yang tidak layak. Pembentukan kendala gomory dihentikan jika solusi integer sudah diperoleh, namun jika solusi integer belum diperoleh maka kendala gomory dibuat lagi. Jika di setiap iterasi tidak ditemukan solusi integer maka tidak ditemukan solusi integer yang layak.

Contoh:

Maksimumkan $Z=5 x_{1}+8 x_{2}$

Dengan kendala $x_{1}+x_{2} \leq 6$

$$
\begin{aligned}
& 5 x_{1}+9 x_{2} \leq 45 \\
& x_{1} \text { dan } x_{2} \text { non negative integer }
\end{aligned}
$$

Solusi dengan primal simpleks:

Iterasi ke 0

\begin{tabular}{|l|l|l|l|l|l|}
\hline $\mathrm{B}$ & $x_{1}$ & $x_{2}$ & $s_{1}$ & $s_{2}$ & $\mathrm{NK}$ \\
\hline$s_{1}$ & 1 & 1 & 1 & 0 & 6 \\
\hline
\end{tabular}




\begin{tabular}{|l|l|l|l|l|l|}
\hline$S_{2}$ & 5 & 9 & 0 & 1 & 45 \\
\hline$Z$ & -5 & -8 & 0 & 0 & 0 \\
\hline
\end{tabular}

Iterasi ke 1

\begin{tabular}{|l|l|l|l|l|l|}
\hline $\mathrm{B}$ & $x_{1}$ & $x_{2}$ & $s_{1}$ & $s_{2}$ & $\mathrm{NK}$ \\
\hline$s_{1}$ & $\frac{4}{9}$ & 0 & 1 & $-\frac{1}{9}$ & 1 \\
\hline$x_{2}$ & $\frac{5}{9}$ & 1 & 0 & $\frac{1}{9}$ & 5 \\
\hline $\mathrm{Z}$ & $-\frac{5}{9}$ & 0 & 0 & $\frac{8}{9}$ & 40 \\
\hline
\end{tabular}

Iterasi ke 2

\begin{tabular}{|l|l|l|l|l|l|}
\hline $\mathrm{B}$ & $x_{1}$ & $x_{2}$ & $s_{1}$ & $s_{2}$ & $\mathrm{NK}$ \\
\hline$x_{1}$ & 1 & 0 & $\frac{9}{4}$ & $-\frac{1}{4}$ & $\frac{9}{4}$ \\
\hline$x_{2}$ & 0 & 1 & $-\frac{5}{4}$ & $\frac{1}{4}$ & $\frac{15}{4}$ \\
\hline $\mathrm{Z}$ & 0 & 0 & $\frac{5}{4}$ & $\frac{3}{4}$ & $\frac{165}{4}$ \\
\hline
\end{tabular}

Solusi yang didapatkan adalah $x_{1}=\frac{9}{4}, x_{2}=\frac{15}{4}$ dan $Z=\frac{165}{4}$.

Nilai $x_{1}$ dan $x_{2}$ bukanlah solusi yang integer. Karena yang diinginkan adalah solusi $x_{1}$ dan $x_{2}$ merupakan bilangan integer maka dibuatlah kendala gomory. Nilai $f_{i}$ terbesar pada nilai $x_{2}$ sehingga dari persamaan kedua didapatkan: $x_{2}-\frac{5}{4} s_{1}+\frac{1}{4} s_{2}=\frac{15}{4}$ atau $x_{2}+\left(-2+\frac{3}{4}\right) s_{1}+\frac{1}{4} s_{2}=3 \frac{3}{4}$ sehingga kendala gomory yang didapatkan adalah $s_{g}-\frac{3}{4} s_{1}-\frac{1}{4} s_{2}=-\frac{3}{4}$. Tabel baru setelah penambahan kendala gomory adalah sebagai berikut: 
Iterasi ke-3

\begin{tabular}{|l|l|l|l|l|l|l|}
\hline $\mathrm{B}$ & $x_{1}$ & $x_{2}$ & $s_{1}$ & $s_{2}$ & $s_{g}$ & $\mathrm{NK}$ \\
\hline$x_{1}$ & 1 & 0 & $\frac{9}{4}$ & $-\frac{1}{4}$ & 0 & $\frac{9}{4}$ \\
\hline$x_{2}$ & 0 & 1 & $-\frac{5}{4}$ & $\frac{1}{4}$ & 0 & $\frac{15}{4}$ \\
\hline$s_{g}$ & 0 & 0 & $-\frac{3}{4}$ & $-\frac{1}{4}$ & 1 & $-\frac{3}{4}$ \\
\hline $\mathrm{Z}$ & 0 & 0 & $\frac{5}{4}$ & $\frac{3}{4}$ & 0 & $\frac{165}{4}$ \\
\hline
\end{tabular}

Dengan penyelesaian menggunakan metode dual simpleks didapatkan hasil seperti berikut:

Iterasi ke-4

\begin{tabular}{|l|l|l|l|l|l|l|}
\hline $\mathrm{B}$ & $x_{1}$ & $x_{2}$ & $s_{1}$ & $s_{2}$ & $s_{g}$ & NK \\
\hline$x_{1}$ & 1 & 0 & 0 & -1 & 3 & 0 \\
\hline$x_{2}$ & 0 & 1 & 0 & $\frac{2}{3}$ & $-\frac{5}{3}$ & 5 \\
\hline$s_{g}$ & 0 & 0 & 1 & $\frac{1}{3}$ & $-\frac{4}{3}$ & 1 \\
\hline $\mathrm{Z}$ & 0 & 0 & 0 & $\frac{1}{3}$ & $\frac{5}{3}$ & 40 \\
\hline
\end{tabular}

Berdasarkan tabel pada iterasi ke-4 didapatkan $x_{1}=0, x_{2}=5$ dan $\mathrm{Z}=40$. Karena solusi $x_{1}$ dan $x_{2}$ yang didapatkan sudah merupakan solusi yang integer maka iterasi selesai.

3. Metode Branch and Bound

Metode Branch and Bound (cabang dan batas) adalah salah satu metode yang sering digunakan untuk menghasilkan penyelesaian optimal program linier yang menghasilkan variable-variable keputusan bilangan bulat. Sesuai dengan namanya, metode ini membatasi penyelesaian optimum yang akan menghasilkan bilangan pecahan dengan cara membuat cabang atas dan bawah bagi masing-masing 
variable keputusan yang bernilai pecahan agar bernilai bulat sehingga setiap pembatasan akan menghasilkan cabang baru.

Langkah-langkah dalam metode branch and bound adalah:

1. Menyelesaikan masalah program linier dengan cara simpleks biasa

2. Meneliti solusi optimumnya. Jika variabel basis yang diharapkan bulat adalah bulat, maka artinya solusi optimum bulat sudah didapatkan/dicapai.

3. Nilai solusi pecah yang layak dicabangkan ke dalam sub-sub masalah, tujuannya adalah untuk menghilangkan solusi kontinu yang tidak memenuhi solusi bulat pada masalah itu.

4. Untuk setiap sub masalah, nilai solusi optimum kontinyu fungsi tujuan ditetapkan sebagai batas atas. Solusi bulat terbaik menjadi batas bawah (pada awalnya, ini adalah solusi kontinyu yang dibulatkan ke bawah). Sub-sub masalah yang memiliki batas atas kurang dari batas bawah yang ada, tidak diikut sertakan pada analisa selanjutnya. Suatu solusi bulat layak adalah sama baik atau lebih baik dari batas atas untuk setiap sub masalah yang dicari. Jika solusi yang demikian terjadi, suatu sub masalah dengan batas atas terbaik dipilih untuk dicabangkan. Kembali ke langkah 3.

Keuntungan dari cara pencabangan dan pembatasan adalah cara yang efisien untuk mendapatkan seluruh jawaban layak (fisibel), sedangkan kerugian cara ini adalah akan mencari seluruh jawaban program linier pada setiap titik. Pada persoalan yang besar akan memerlukan waktu yang cukup lama.

Contoh:

Maksimumkan $Z=5 x_{1}+8 x_{2}$

Dengan kendala $x_{1}+x_{2} \leq 6$

$$
\begin{aligned}
& 5 x_{1}+9 x_{2} \leq 45 \\
& x_{1} \text { dan } x_{2} \text { non negatif integer }
\end{aligned}
$$

Solusi yang didapatkan adalah dengan metode simpleks adalah $x_{1}=\frac{9}{4}=2.25, \quad x_{2}=\frac{15}{4}=3.75$ dan $\mathrm{Z}=\frac{165}{4}=41.25$. Solusi integer dengan metode Branch and Bound didapatkan dengan mencabangkan masalah tersebut menjadi dua bagian dengan menambahkan pembatas untuk variabel yang memiliki nilai bagian 
pecah yang terbesar kemudian setiap percabangan masalah diselesaikan dengan metode simpleks untuk dicari nilai optimumnya. Variabel terpilih untuk dilakukan percabangan adalah $x_{2}$ sehingga didapatkan pembatas baru yaitu $x_{2} \leq 3$ dan $x_{2} \geq 4$. Masalah yang didapatkan adalah:

Bagian A. Maksimumkan $Z=5 x_{1}+8 x_{2}$

Dengan kendala $x_{1}+x_{2} \leq 6$

$$
\begin{aligned}
& 5 x_{1}+9 x_{2} \leq 45 \\
& x_{2} \leq 3 \\
& x_{1}, x_{2} \geq 0
\end{aligned}
$$

Bagian B. Maksimumkan $Z=5 x_{1}+8 x_{2}$

Dengan kendala $x_{1}+x_{2} \leq 6$

$$
\begin{aligned}
& 5 x_{1}+9 x_{2} \leq 45 \\
& x_{2} \geq 4 \\
& x_{1}, x_{2} \geq 0
\end{aligned}
$$

Solusi untuk masalah bagian A adalah $Z=39, x_{1}=3, x_{2}=3$

Solusi untuk masalah bagian B adalah $Z=41, x_{1}=1.8, x_{2}=4$

Pada masalah bagian A sudah didapatkan solusi yang semuanya bulat, akan tetapi masalah bagian B solusinya masih ada yang pecahan, sehinga masih memungkinkan untuk dicari solusi bulat lainnya yang nilainya mungkin lebih besar dari solusi masalah $\mathrm{A}$. Dengan demikian masalah B dapat dicabangkan lagi menjadi dua bagian yaitu B1 dan B2 dengan menambahkan kendala $x_{1} \leq 1$ dan $x_{2} \geq 2$.

Bagian B1. Maksimumkan $Z=5 x_{1}+8 x_{2}$

Dengan kendala $x_{1}+x_{2} \leq 6$

$$
\begin{aligned}
& 5 x_{1}+9 x_{2} \leq 45 \\
& x_{2} \geq 4 \\
& x_{1} \leq 1 \\
& x_{1}, x_{2} \geq 0
\end{aligned}
$$


Bagian B2. Maksimumkan $Z=5 x_{1}+8 x_{2}$

Dengan kendala $x_{1}+x_{2} \leq 6$

$$
\begin{aligned}
& 5 x_{1}+9 x_{2} \leq 45 \\
& x_{2} \geq 4 \\
& x_{2} \geq 2 \\
& x_{1}, x_{2} \geq 0
\end{aligned}
$$

Solusi dari masalah bagian B1 adalah $\mathrm{Z}=40.55, x_{1}=1, x_{2}=4.44$ Untuk bagian B2 tidak ada solusi yang fisibel

Berdasarkan solusi tersebut maka masalah B1 dapat dicabangkan lagi menjadi dua masalah yaitu B1a dan B1b dengan menambahkan kendala $x_{2} \leq 4$ dan $x_{2} \geq 5$. Dengan penambahan kendala $x_{2} \leq 4$ pada bagian B1a tersebut didapatkan $Z=37$, $x_{1}=1$ dan $x_{2}=4$. Penambahan kendala $x_{2} \geq 5$ pada bagian B1b mengakibatkan nilai $Z=40, x_{1}=0$ dan $x_{2}=5$. Pencarian solusi integer sudah selesai dengan didapatkannya solusi pada bagian B1a dan B1b kedua-duanya integer. Dari semua pencarian solusi integer, yang menghasilkan solusi integer maksimum adalah pada bagian B1b dengan hasil $\mathrm{Z}=40, x_{1}=0$ dan $x_{2}=5$. Ringkasan semua hasil pencarian solusi dapat digambarkan dalam diagram 1 berikut: 


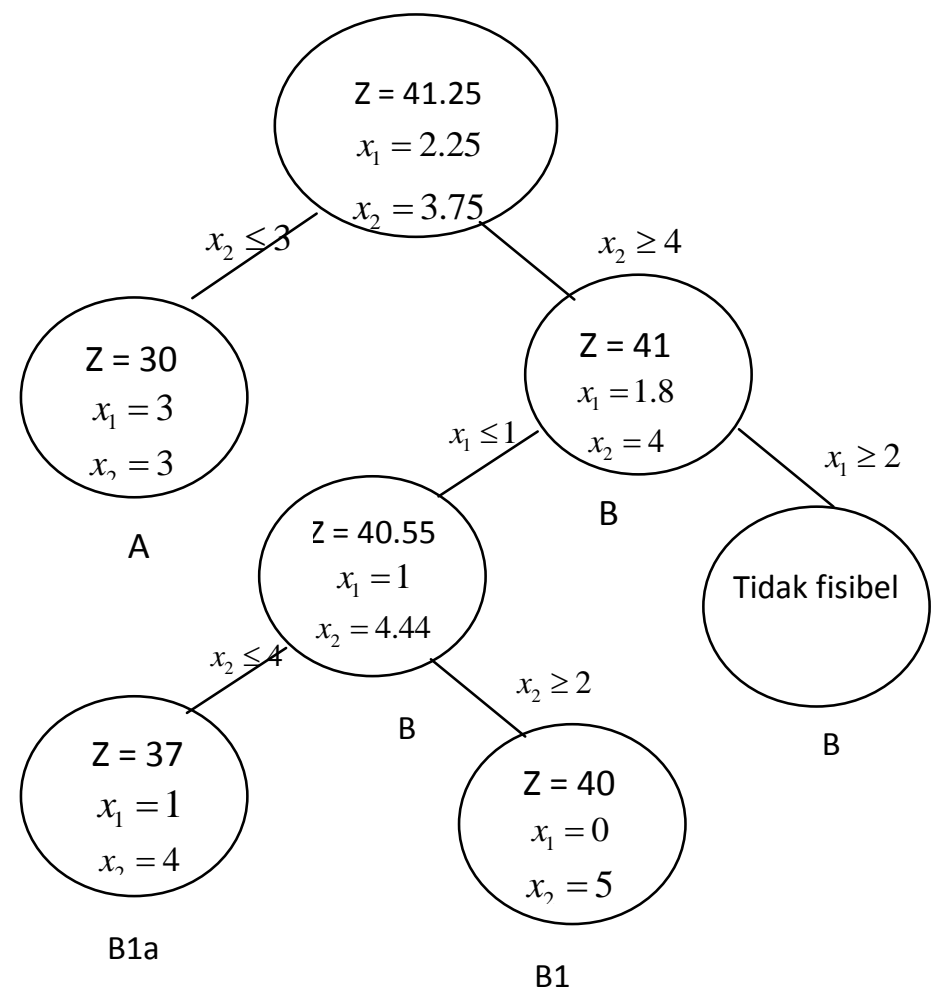

Diagram 1

Untuk kasus minimum dapat digambarkan dalam diagram 2 berikut:

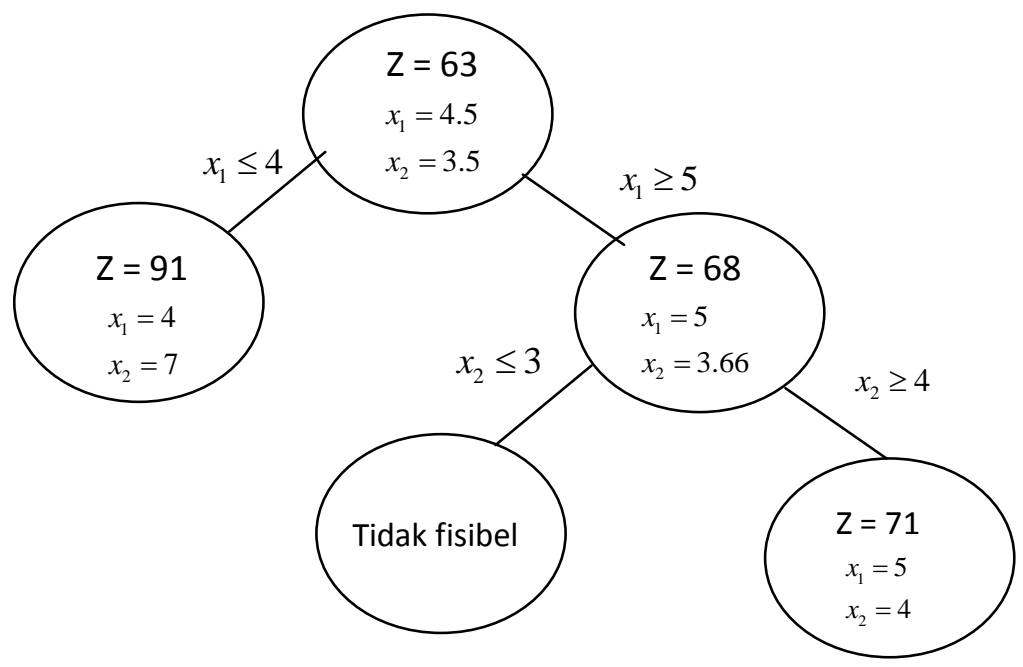

Diagram 2 
Untuk kasus minimasi di atas solusi integer minimasinya adalah $\mathrm{Z}=71$ dengan $x_{1}=5$ dan $x_{2}=4$

\section{Kesimpulan:}

Penggunaan metode Branch and Bound sedikit sekali kesalahannya namun memerlukan perhitungan yang lebih banyak. Sedangkan metode Cutting Plane lebih cepat mencapai optimal karena dengan penambahan kendala gomory efektif menghilangkan solusi yang kontinu. Metode Gomory lebih baik digunakan jika variabelnya sedikit. 


\section{DAFTAR PUSTAKA}

Aminuddin, 2005, Prinsip-prinsip Riset Operasi, Erlangga, Jakarta

Hamdy A. Taha. 1996. Riset Operasi. Binarupa Aksara, Jakarta

Hillier, F.S. dan Lieberman, G.J., (1995), Introduction to Operation Research, Holden Day, Inc. USA.

kiayati.staff.gunadarma.ac.id/Downloads/files/.../Program-Integer.pdf

Yuhendra Ajeng dkk. 2011. Integer Programming Dengan Pendekatan Metode Branch And Bound Dan Metode Cutting Plane Untuk Optimasi Kombinasi Produk. Jurnal Matematika FMIPA Universitas Brawijaya. 